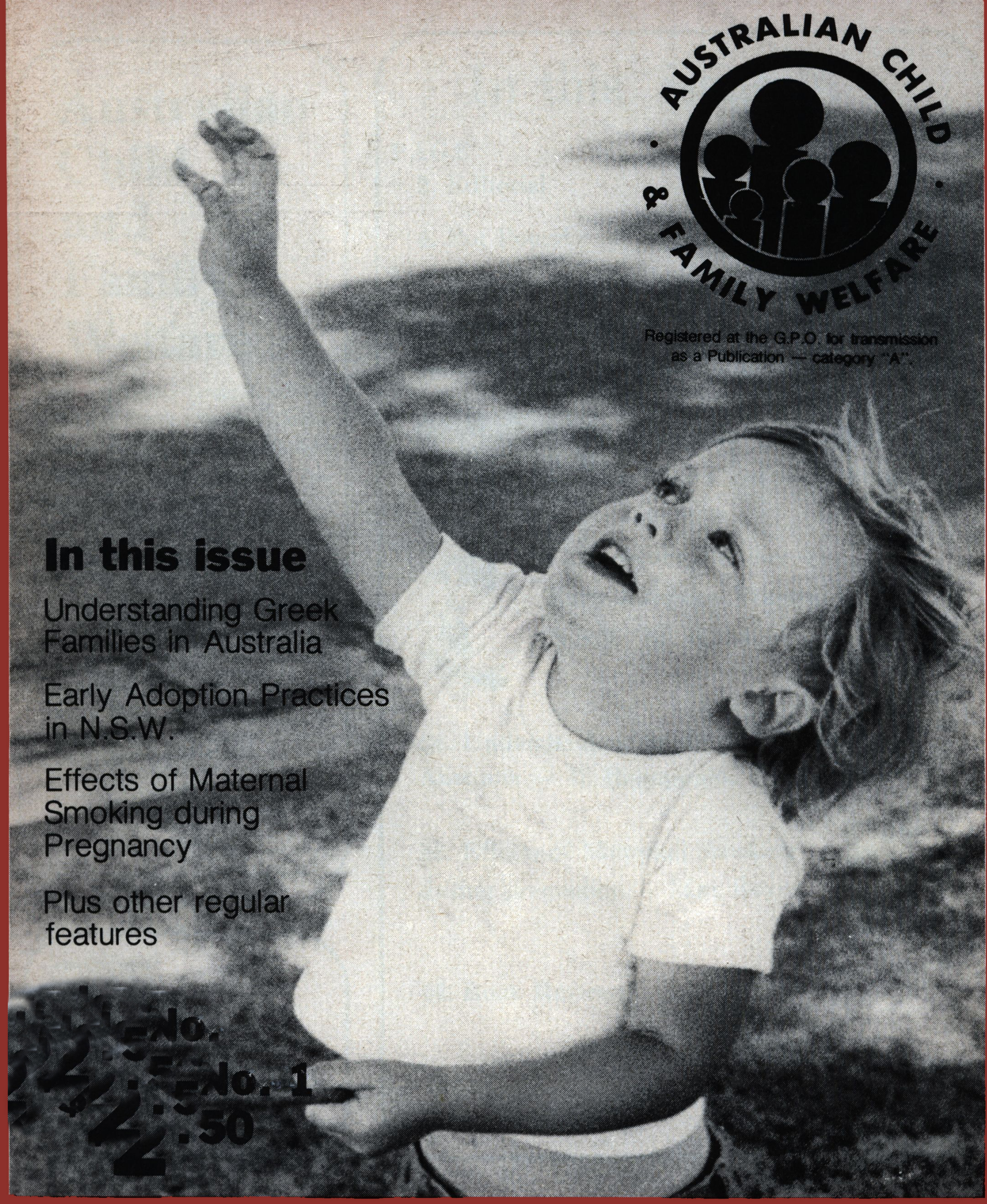


National Library of Australia Card No. and ISSN No. 03128970

Photographs:-

Andrew Blake, Colin Knox,

Robert Ashton/Scoopix, Howard Birnstihl Pauline Reynolds 


\section{Australian Child}

\section{and}

Family

Welfare

is the quarterly journal of the Child and Family Welfare Council of Australia and is published by the Children's Welfare Association of Victoria.

\section{Committee}

Editor

Cliff Picton

Associate Editor Denis Oakley

Business Manager David Thackray

Committee Members

Barbara Spaulding

John Edwards

Bill Hughes

Neale Molloy

Max Liddell

Graeme Gregory

\section{ADVERTISING}

Geoff Goullet, Suite 2.

65 Queens Road,

MELBOURNE. 3004.

Telephone 516238 .

PRINTER:

Pilgrim Printing Services,

11 Sheridan Court, Heathmont,

Victoria, 3135.

Telephone: 7295828 .

\section{In this issue ...}

PAGE

\section{Editorial}

4. Pot Pourri

7. The Royal Commission on

Human Relations. A

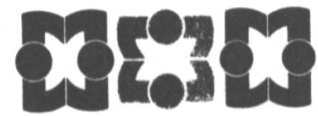

comment on some issue - Richard Chisholm.

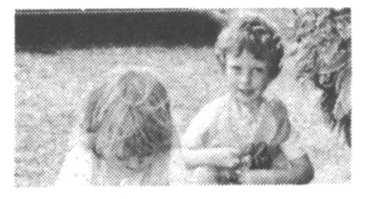

\section{Parents and Children}

in Day Care - B. Potter.

\section{Insecure Families -}

Early Adoption Practice in

N.S.W. M. Horsborough

24. Understanding the Greek Family in Australia - L. Rodopoulos.

38. Effects of Maternal Smoking during pregnancy - Max Boyce.

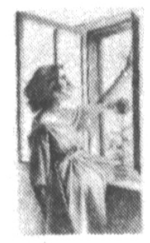

44. Book Reviews

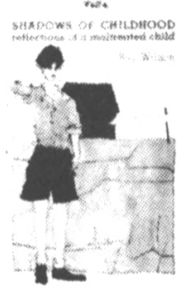




\section{Let's restore the Balance.}

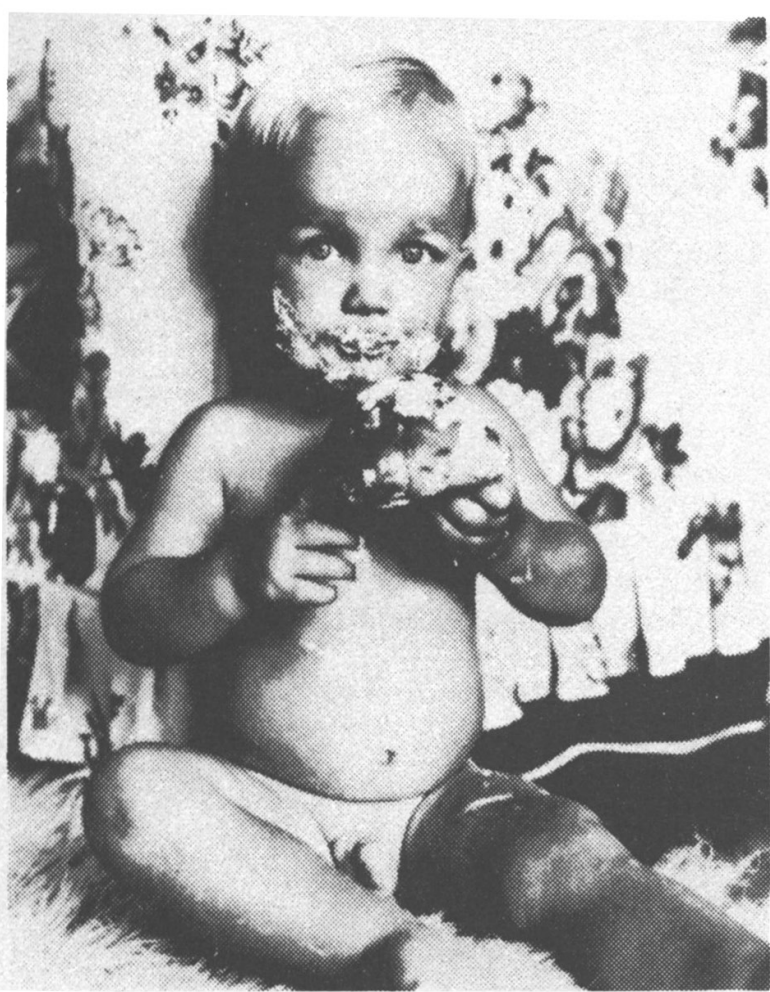

Photo by courtesy of Vivian Jenkins and 'Cleo'

\section{It's not a question of charity.}

It is a matter of justice.

A handful of rich nations-ours among them-consuming most of the world's resources.

The rest ... two thirds of the world . . some three billion human beings... living lives plagued by hunger and disease and deprived of basic necessities.

The have's and the have-not's. On a global scale.

\section{You can help restore the balance.}

Through Foster Parents Plan you can do something. No, you will not change the world. But you will be assisting a family towards the self sufficiency that is their due as human persons.

We have no political or religious affiliations. Our sole purpose is to help people in the developing nations to help themselves ... through the support of those who care.

\section{Do you care? Enough to help?}

You can sponsor a family in Latin America, Asia or Africa. It will cost you $\$ 14.50$ a month. This contribution provides the family with vital counselling. guidance and encouragement from an indigenous social worker. It provides some financial support, medical care, health education and vocational training

It is small assistance by our standards. Yet it lays a foundation for future progress by the family's own efforts.

Our objective: nol dependency, but initiative and selfreliance.

Person to person help.

You will be put in touch with the family and kept informed of its progress. One of the children (the "Foster Child") will

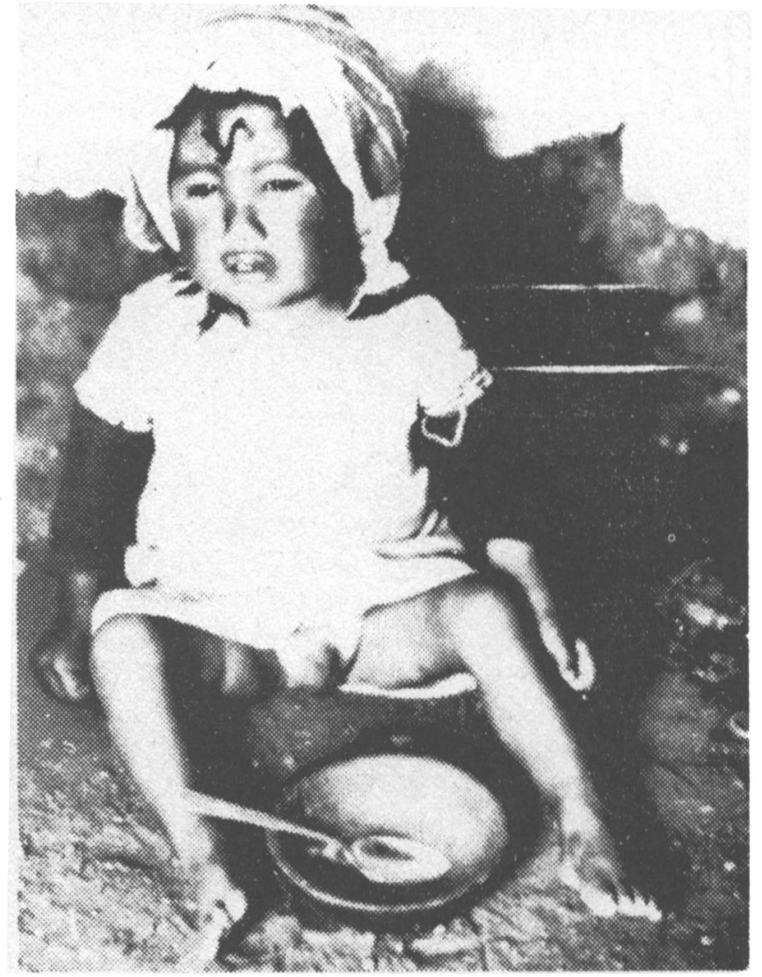

write to you regularly. It need not be just a matter of doliars and cents.

There can be personal interest and personal involvement. Perhaps you cannot commit yourself to full sponsorship. Then just send what you can. It will be put to good use in family, community self-help projects and co-operatives.

Foster Parents Plan of Australia is currently at work in Ethiopia, Bolivia, Brazil, Colombia, Ecuador, Haiti, Peru, Indonesia (Bali \& Yogyakarta), Republic of Korea and the Philippines.

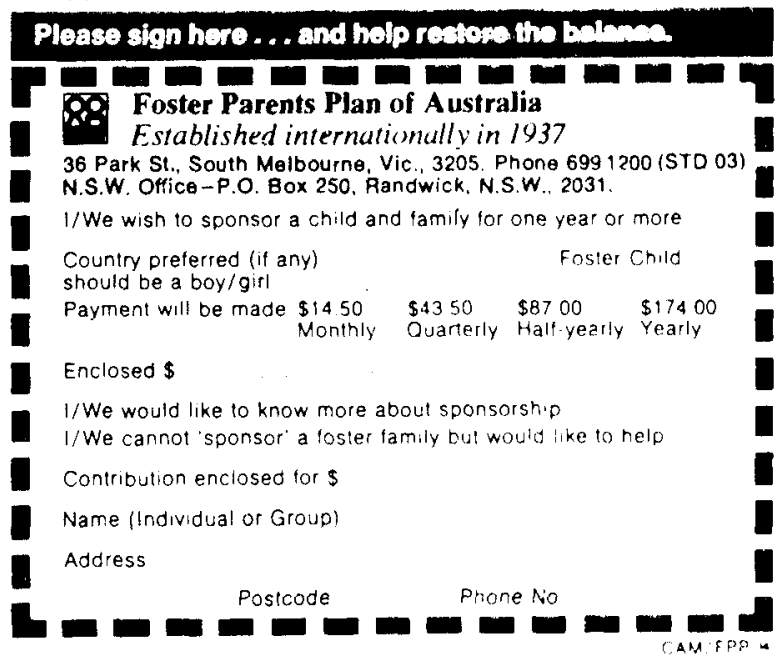

